\title{
Soft ferrite cores characterization for integrated micro-inductors
}

\author{
Yen Mai Nguyen ${ }^{1,3}$, David Bourrier ${ }^{1,3}$, Samuel Charlot ${ }^{1,3}$, Zarel Valdez-Nava ${ }^{2,3}$, Vincent Bley ${ }^{2,3}$, \\ Céline Combettes $^{2,3}$, Thomas Lopez ${ }^{1}$, Jean-Pierre Laur ${ }^{1,3}$, Magali Brunet ${ }^{1,3}$ \\ ${ }^{1}$ CNRS, LAAS, 7 avenue colonel Roche, F-31400 Toulouse, France \\ ${ }^{2}$ CNRS, LAPLACE, 118 route de Narbonne, F-31062 Toulouse, France \\ ${ }^{3}$ Université de Toulouse; UPS, INPT; LAAS, LAPLACE, Toulouse, France \\ Email:mbrunet@laas.fr
}

\begin{abstract}
Low profile soft ferrite films constitute a competitive solution for the integration of microinductors on silicon in low-power medium frequency DC-DC conversion applications. High resistivity of soft ferrites is indeed a major advantage for operating frequencies in the range of 5-10 MHz. We have studied several soft ferrites including commercial ferrite films and inhouse made ferrites. Test inductors were fabricated at wafer level using micromachining and assembling techniques. The proposed process is based on a sintered ferrite core placed in between thick electroplated copper windings. The low profile ferrite cores of $1.2 \times 2.6 \times 0.1$ $\mathrm{mm}^{3}$ were produced by two methods issued from green tape-casted films or ferrite powders. This article presents the magnetic characterization of the fabricated ferrite cores cut and printed in rectangular shape and sintered at different temperatures. The comparison is made in order to find out the best material for the core that can offer the micro-inductor a high inductance in the range of $200-1000 \mathrm{nH}$ at $6 \mathrm{MHz}$ and that generate the smallest losses. With commercial ferrite core, it is demonstrated, thanks to a test inductor, that an inductance density of $215 \mathrm{nH} \cdot \mathrm{mm}^{-2}$ up to $6 \mathrm{MHz}$ could be reached. Extracted losses at $6 \mathrm{MHz}$, under $10 \mathrm{mT}$ are in the range of 0.8 to $2.5 \mathrm{~W} \cdot \mathrm{cm}^{-3}$.
\end{abstract}

Key words: Micro inductor, ferrite, on-chip integration, Power SoC

\section{Introduction}

The trend towards miniaturization of mobile electronic products with the demand of improving functionality and performance raises challenges for power management systems for which higher power density with higher energy conversion efficiency is required. In advanced DC-DC converters, the control circuits and power semiconductor devices can be fully integrated but the passive components especially inductors and transformers are still obstacles for further reducing the size of DC-DC converters. A lot of researches have been carried out to achieve inductor integration on-chip or in-package. Some demonstrators of air-core inductors, thin film magnetic inductors, and ferrite based ones have shown that each integration method has its own merit and difficulties [1-15]. For on-chip integration, the approaches to the fabrication of micro-inductors involving vacuum deposition and electrodeposition of magnetic cores have been demonstrated over the last thirty years. Vacuum deposition techniques, i.e. sputtering or evaporation, can be used to deposit a wide range of magnetic materials including alloys and oxides such as Ni-Fe-Zr based, Co-Zr based, Co-Hf-Ta-Pd, Co-Fe-Hf-O, $\mathrm{Ni}_{80} \mathrm{Fe}_{20}$, Fe-B-N or Fe-Co-based amorphous thin films $[7,16]$. Despite the disadvantage of slow deposition rate, these sputtered materials usually have good soft 
magnetic properties: amorphous alloys exhibit typically high induction saturation $(>1 \mathrm{~T})$ and small coercive field (several Oe). On the other hand, oxides have high electrical resistivity which allows characteristics to be maintained up to the $\mathrm{GHz}$ range [16]. However, when the film is thicker than several micro-meters, stress can develop in the layer and etching of thick metallic films is an issue. Dry etching of thick films usually involves long etching times resulting in heating of the substrate and degradation of the magnetic film properties while wet etching of thick films results in severe undercutting. Alternatively, sputtered films have been deposited through shadow masks up to tens of microns [17]; however the problem of delamination and cracking still happened for the second layer of deposition due to an unfortunate issue of over-heating within the chamber. Electroplating is a less costly method than vacuum deposition techniques and more suitable for micro-inductor cores with large cross-sectional areas. The films deposited by electroplating have thickness of several micro-meters to several tens of micro-meter including alloys of $\mathrm{NiFe}$ with different composition such as $\mathrm{Ni}_{80} \mathrm{Fe}_{20}, \mathrm{Ni}_{45} \mathrm{Fe}_{55}, \mathrm{Ni}_{50} \mathrm{Fe}_{50}$ and others like CoFeNiC, $\mathrm{CoPFe}, \mathrm{CoNiFe}, \mathrm{CoFeCu}, \mathrm{NiFeMo}[11,18,19]$. With this technique, only conductive materials can be electroplated; so, due to high frequency operation eddy currents can be considerable and should be controlled by lamination. Recently, laminated thick films of electroplated metallic alloys were demonstrated for CoNiFe with about 40 layers, $1 \mu \mathrm{m}$ thick for each layer. The test inductor demonstrated a constant inductance of $1.6 \mu \mathrm{m}$ up to $10 \mathrm{MHz}$, indicating suppressed eddy current losses [12].

Screen printing of ferrite powder or magnetic composites is an alternative approach compared to the two above-mentioned methods [20,21]. It has some fabrication advantages such as fast deposition and much larger achievable thickness up to several hundreds of micro-meter.

In terms of performance, soft ferrite materials present an interesting solution for integration, in particular NiZn ferrites with formula $\mathrm{Me}_{x} \mathrm{Ni}_{\mathrm{y}} \mathrm{Zn}_{\mathrm{z}} \mathrm{Fe}_{2} \mathrm{O}_{4}$ where Me refers to transition divalent metals with $\mathrm{x}+\mathrm{y}+\mathrm{z}=1$. They are usually employed for realizing bulk inductors and/or LTCC low profile inductors [22,23]. Their high resistivity, in the range of $10^{3}-10^{6} \Omega . \mathrm{m}$ would tend to minimize eddy current losses at high frequencies and the coercive field ranges from less than 1 Oe to several Oe. Losses of NiZn ferrites are in the range of 100-1000 mW.cm ${ }^{-3}$ at $3 \mathrm{MHz}$ under $10 \mathrm{mT}$ [24]. Besides, their permeability can be relatively high: from tens to hundreds and induction saturation is around 0.20-0.30 T. Composition and microstructure largely influence magnetic properties of NiZn ferrites. Moreover, the ferrite powder needs to be sintered at high temperature (usually about $900^{\circ} \mathrm{C}$ ) to achieve desired magnetic properties. Regarding CMOS compatibility, such high temperatures can be a problem for most materials already presented on the substrate but there are some ways to tackle this issue. For integrated ferritebased micro-inductors, some authors have done sintering of the bottom ferrite layer for spiral-type inductors then completing with a composite top layer [8], some have done sintering of the bottom and top ferrite layer in-situ [25]. Others have developed hybrid solutions where the core is fabricated off-chip [15].

In general, however, ferrite-based inductors reported in literature are either bulky when the core is realized offchip $[4,26]$, either they don't show optimal performance due to the fact that ferrite material is not sintered or it is mixed with polymer [8,27,28]. In [8] for instance, the magnetic composite layer has low permeability of 25 while the fully-sintered magnetic layer has higher permeability of 120. In the case of the micro-inductors in the toroidal structure reported by Fang [27] the permeability of the non-sintered magnetic composite core (Mn-Zn) is only 5 . 
Consequently, the fabricated inductor has an inductance of about $40 \mathrm{nH}$ for a foot print of $3 \mathrm{~mm}^{2}$, corresponding hence to $15 \mathrm{nH} . \mathrm{mm}^{-2}$ in density. Micro-inductors with Ni-Zn ferrite composite in spiral and pot-core designs have shown inductance densities about $40 \mathrm{nH} \cdot \mathrm{mm}^{-2}$ for footprint of 9 and $20 \mathrm{~mm}^{2}$ respectively [26,28]. With these ferrite/polymer composites, core losses have not been reported.

Thanks to the adequate thickness and pre-eminent magnetic properties, fully-sintered ferrite-based cores offer high inductance densities for the integrated inductors. In our previous works [29,30], we presented a possible solution for integrating very small size $\left(<4 \mathrm{~mm}^{2}\right)$ micro-inductor in a PwrSoC (Power system on Chip), based on the hybrid integration on silicon substrate of fully sintered ferrite cores with windings made from electroplated copper. This article presents the full characterization of low-profile ferrite cores with a focus on losses in the range of frequency of interest (above $1 \mathrm{MHz}$ ). Four materials are compared: cores either cut from commercial films or screen printed from an in-house made paste. We believe that this approach presents a low-cost solution due to minimum number of fabrication steps and high throughput deposition techniques: electroplating for copper windings and screen printing or milling for cores.

After developing target specifications based on realistic applications and after proposing a preliminary design for the micro-inductors, section 3 presents the fabrication processes for realizing ferrite cores and test microinductors. In the last section, results of magnetic and electrical characterization are presented in details for the four materials, with B-H curves, complex permeability, inductance performance and core losses. The effect of sintering temperature on the performance is eventually discussed.

\section{Specifications, material choices and design}

In order to achieve an integration of the inductor with high specific inductance, while keeping low losses, frequencies in the MHz range are selected. The specifications, defined according to typical commercial inductors, are the following: an inductance in the range of $200-1000 \mathrm{nH}$, an equivalent series resistance in the range of $0.1 \Omega$ $0.2 \Omega$ at bias current of $0.6 \mathrm{~A}$ and operating at $6 \mathrm{MHz}$. In the objective of evaluating performance prior to inductor fabrication, several NiZn ferrites were selected among which:

- Commercial ferrite films by ESL ElectroScience [31,32]: ESL 40010® and ESL40011® with expected permeabilities of 60 and 200 respectively. These materials were characterized at macro-scale by $\mathrm{Mu}$ et al [24]. At $1.5 \mathrm{MHz}$ and $20 \mathrm{mT}$, losses of $1000 \mathrm{~mW} \cdot \mathrm{cm}^{-3}$ and $2000 \mathrm{~mW} \cdot \mathrm{cm}^{-3}$ were measured for 40010 and 40011.

- In-house made ferrite powders, namely U70 and U200 based on ref. [33] that will be mixed into a paste for screen printing deposition. Selected ferrites are $\mathrm{NiZnCuCo}$ with a ratio of $\mathrm{Ni} / \mathrm{Zn}$ fixed to a value of 0.55 for U70 and 0.43 for U200: the smaller the ratio of $\mathrm{Ni} / \mathrm{Zn}$ the higher the permeability of ferrite according to previous work [33]. Cobalt was added 3.5 at $\%$ in selected ferrites in order to increase the cut-off frequency and decrease losses: $200 \mathrm{~mW} . \mathrm{cm}^{-3}$ at $1.5 \mathrm{MHz}$ under $25 \mathrm{mT}$ were reported.

The simplest micro-inductor topology in terms of core fabrication is a thin film ferrite in a rectangular shape wrapped by multi-level metal windings as shown in figure 1 . The total thickness of the micro-inductor should be less than $250 \mu \mathrm{m}$ to constitute a competitive solution in comparison to current commercial inductors, for example 
LPS3010 inductor by Coilcraft [34]. To avoid difficulties in fabrication, the thickness of copper windings is fixed to $50 \mu \mathrm{m}$. In the design, the final realized micro-inductor will have the winding forming by bottom copper tracks, vias and top copper tracks (see figure 1). Hence, the magnetic core is limited to a thickness of $150 \mu \mathrm{m}$.

Based on target specifications of the inductor, the design was made by adjusting parameters of the core and winding dimensions. The geometrical input parameters are: core width $(X)$, core length $(Y)$, magnetic core width $(w)$, magnetic core thickness $(t)$, thickness and width of copper wire and number of turns $(N)$. The output parameters are the DC and AC resistance, the total inductance and maximum magnetic induction. Design was done by Excel with analytical expressions. In the constrained dimension, the combination of $X, Y, w$ and $N$ that give the best output of total inductances, DC and AC resistances was selected for the test inductor. We have checked that with $\mathrm{B}_{\text {sat }}$ about $0.25 \mathrm{~T}$, the inductors would operate normally at $0.6 \mathrm{~A} \mathrm{DC}$ and reach specifications. This preliminary design is necessary to define realistic core dimensions, i.e. close to optimized version. Defined dimensions for full inductors are $1.54 \times 2.64 \mathrm{~mm}^{2}$ with the magnetic core width of $350 \mu \mathrm{m}$; these cores will be integrated in the microinductor with 21 turns of winding. Permeability and core loss density characterization of the developed ferrite materials shaped in the chosen dimensions will be carried out. Eventually, future design optimization will include these magnetic properties.
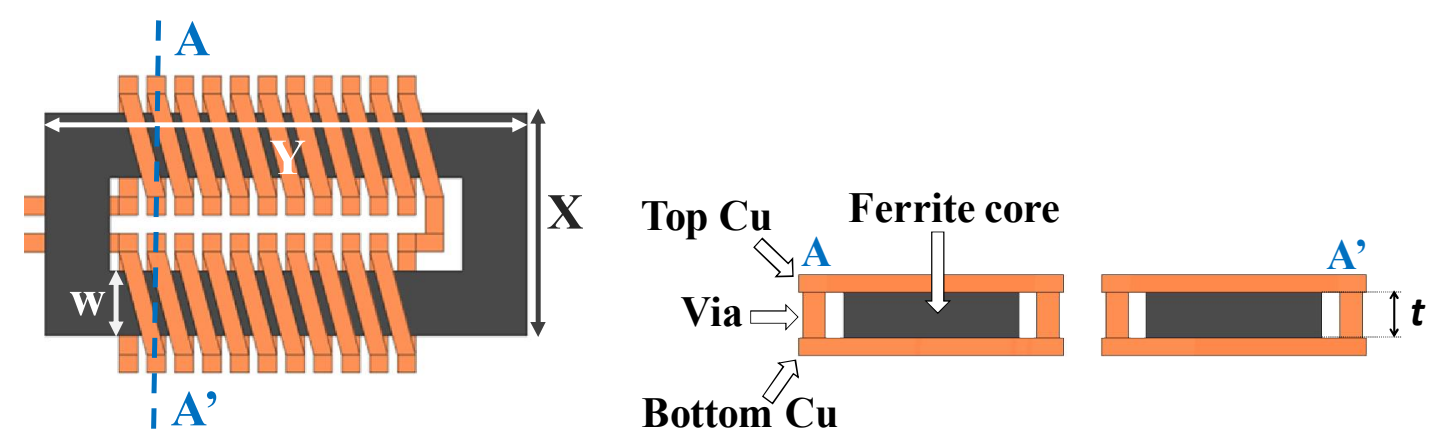

Figure 1. Schematic design of proposed final micro-inductors with top-view and cross section

\section{Experimental}

We propose two approaches for the fabrication of ferrite cores according to their nature:

- From commercial ferrite films: ESL 40010® and ESL 40011® which will be named 40010 and 40011 respectively in the rest of the article. Two layers of thin film ferrite about $70 \mu \mathrm{m}$ each were bonded together by applying a pressure of $800 \mathrm{~N} / \mathrm{cm}^{2}$ in 10 minutes at $90^{\circ} \mathrm{C}$ under vacuum of $10^{-3}$ mbar in a wafer bonding machine AML AWB04. The double-layer films (140 $\mu \mathrm{m}$ thick) were then cut by a micro-milling machine Réalméca RV2 SP (200 $\mu \mathrm{m}$ end mill); the cutting dimensions were adjusted for shrinkage occurring during the sintering phase of these materials.

- From the in-house ferrite powder: synthesized NiZn ferrite powder was mixed with organics including binders, plasticizers, and dispersants provided by ESL ${ }^{\circledR}$ to form magnetic slurry. Dry film photo-resists were used to form $190 \mu$ m-thick moulds on Kapton ${ }^{\circledR}$ polyimide substrates by photolithography technique. The ferrite paste 
was then filled into the mould by screen printing technique using DEK Horizon 01i equipment, followed by thirty minutes vacuum treatment to degas the paste via a mechanical rotary pump. The ferrite composite was dried at $110^{\circ} \mathrm{C}$ for ten minutes and then collected manually after the photo-resist was removed.

Sintering temperature of each ferrite was determined after the shrinkage peaks were identified by thermomechanical analysis using Setsys Evolution TMA. Based on TMA curves, the milled cores were sintered at $885^{\circ} \mathrm{C}$ and $950^{\circ} \mathrm{C}$ under flux of oxygen during 3 and 2 hours respectively. The printed cores were sintered at $980^{\circ} \mathrm{C}$ during 2 hours. The footprint of cut and printed cores after sintering is about $1.2 \times 2.6 \mathrm{~mm}^{2}$. Core thicknesses were measured after sintering: for milled cores, thickness ranges between $108-110 \mu \mathrm{m}$; for printed cores thickness ranges between 90 and $105 \mu \mathrm{m}$. Microstructures of cores were observed by scanning electron microscopy Hitachi S4800. Compositions of different ferrites were estimated by energy dispersive analysis (EDS). The magnetic properties of thin film ferrites were characterized by a vibrating sample magnetometer Versalab ${ }^{\mathrm{TM}}-3$ Tesla Cryogen-free from Quantum Design. To extract the complex permeability ( $\mu$ ' and $\mu^{\prime \prime}$ ) of the used ferrite materials, tore-shape samples were also prepared and measured in a magnetic material test fixture Agilent 16454A on an impedance analyzer Agilent 4294A. The dimension of tore samples was selected according to the sizes of the fixture holders in the test kit. Tores of ESL ferrite films have the internal diameter of $4 \mathrm{~mm}$, the external diameter of $6 \mathrm{~mm}$ and the thickness of $108 \mu \mathrm{m}$. Tores of U70 and U200 home-made ferrites have dimension of $5 \mathrm{~mm}, 14$ $\mathrm{mm}$ and $1.5 \mathrm{~mm}$ as internal diameter, external diameter and thickness.

Eventually, in order to extract magnetic properties such as inductance and core losses, test inductors were fabricated: $50 \mu \mathrm{m}$ thick copper bottom tracks are deposited on $\mathrm{Si} / \mathrm{SiO} 2 / \mathrm{Ti} / \mathrm{Au}$ wafer by photolithography and electroplating. The seed layer is removed after electroplating by wet etching in potassium iodide solution $\mathrm{KI}+\mathrm{I}_{2}$ and HF acid. For test inductors, ground-signal-ground contact pads and a ground ring around the inductor are created in order to test the device under RF probes. Sintered ferrite cores are placed on $\mathrm{Cu}$ tracks and gold $25 \mu \mathrm{m}$-diameter micro-wires are bonded by ball wire bonding technique to complete the winding.

Figure 2 shows a ferrite core after sintering and a test inductor with wire-bonds. These test inductors were characterized by an impedance analyzer (Agilent 4294) to determine the inductance versus frequency and versus DC bias and on a LCR meter (Agilent 4284A) to extract core losses versus AC current (rms).
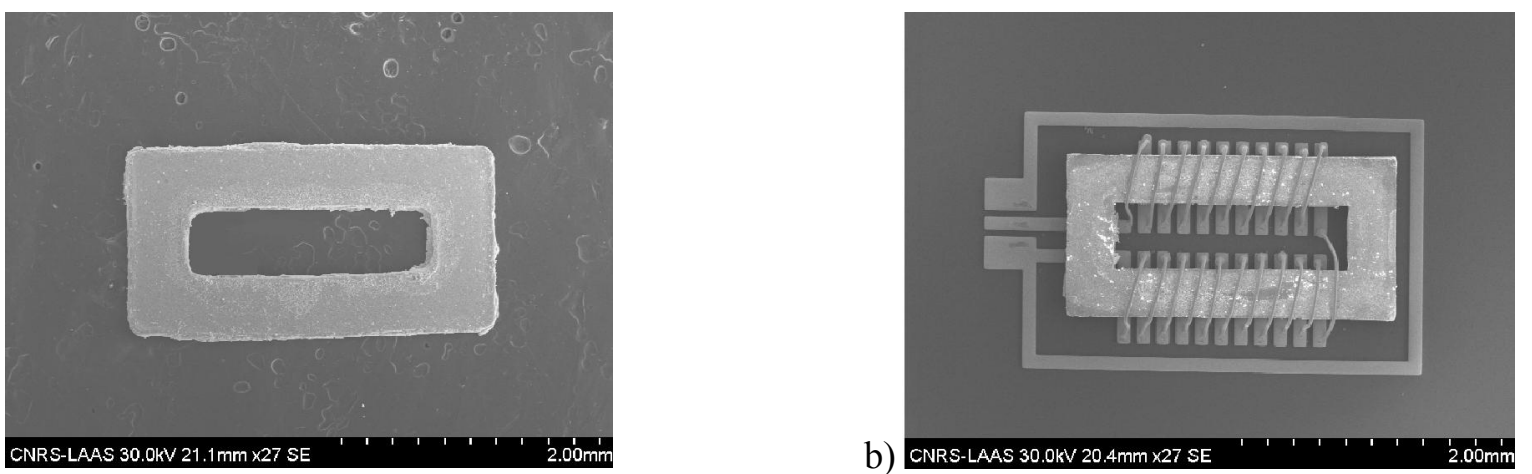

Figure 2. (a) Microscope image of ESL \& thin-film milled cores after sintering and (b) SEM image (top view) of the test inductor with printed core and with wire-bonds to complete magnetic circuits. 


\section{Results and discussion}

\subsection{Magnetic material characterization}

Figure 3 shows the microstructure of different ferrites after sintering. The grains of thin-film 40010 and 40011 have a bimodal distribution, with large grains of 5-8 $\mu \mathrm{m}$, covering around $50 \%$ of the volume, and small grains of $2-3$ $\mu \mathrm{m}$ in diameter. Grain sizes of printed ferrite U70 and U200 are in the range of 1.5-6 $\mu \mathrm{m}$. For all cores, the shrinkage was measured to be $15-20 \%$ with no cracks. The compositions of these ferrites are listed in table 1 .

The B-H characteristics of ferrites are presented in figure 4. The measured samples are free-standing, about 110 $\mu \mathrm{m}$ thick in a square dimension of $2 \times 2 \mathrm{~mm}^{2}$. The induction saturation is in the range of 0.25-0.30 $\mathrm{T}$, with a coercive field of 0.8-5.8 Oe (or 53-462 A/m). 40010 exhibits the highest coercive field which is due to the highest amount of magnetic phase ( $\mathrm{Ni}$ and $\mathrm{Fe}$ ) in 40010 ferrite compared to other ferrites ; a similar effect was observed when doing some copper substitution into $\mathrm{Ni}-\mathrm{Zn}$ ferrites [35]. Magnetic remanences are $0.8-8 \%$ of the saturation magnetization.

Table 1: Composition of different ferrites estimated by SEM-EDS

\begin{tabular}{|l|l|}
\hline Ferrite & Composition \\
\hline $40010(\mathrm{Ni} / \mathrm{Zn}=1.49)$ & $\mathrm{Ni}_{0.49} \mathrm{Zn}_{0.33} \mathrm{Cu}_{0.18} \mathrm{Fe}_{2} \mathrm{O}_{4}$ \\
\hline $40011(\mathrm{Ni} / \mathrm{Zn}=0.47)$ & $\mathrm{Ni}_{0.28} \mathrm{Zn}_{0.60} \mathrm{Cu}_{0.12} \mathrm{Fe}_{2} \mathrm{O}_{4}$ \\
\hline $\mathrm{U} 70(\mathrm{Ni} / \mathrm{Zn}=0.55, \mathrm{Co}=0.035)$ & $\left(\mathrm{Ni}_{0.30} \mathrm{Zn}_{0.55} \mathrm{Cu}_{0.15}\right)_{0.965} \mathrm{Co}_{0.035} \mathrm{Fe}_{2} \mathrm{O}_{4}$ \\
\hline $\mathrm{U} 200(\mathrm{Ni} / \mathrm{Zn}=0.43, \mathrm{Co}=0.035)$ & $\left(\mathrm{Ni}_{0.24} \mathrm{Zn}_{0.56} \mathrm{Cu}_{0.20}\right)_{0.965} \mathrm{Co}_{0.035} \mathrm{Fe}_{2} \mathrm{O}_{4}$ \\
\hline
\end{tabular}
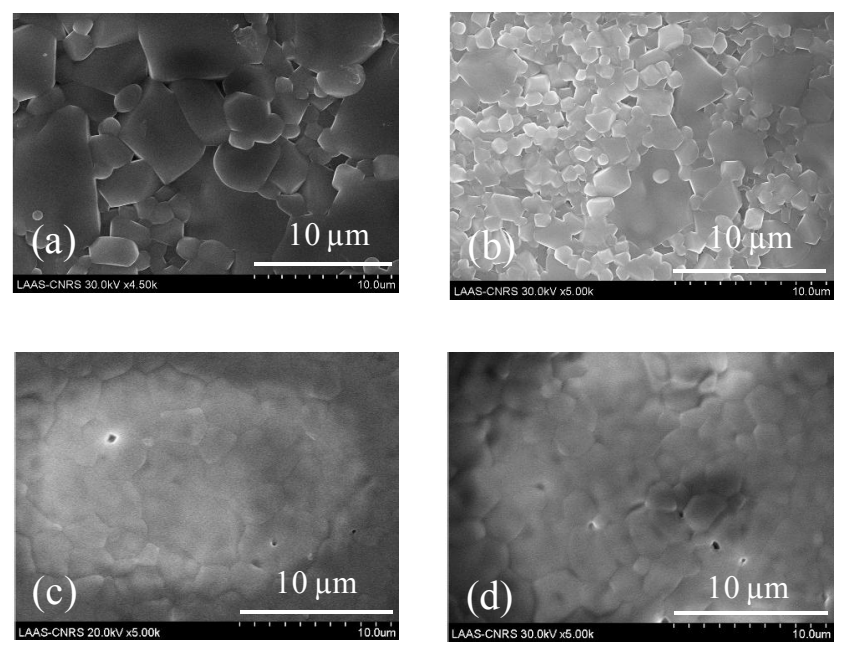

Figure 3. SEM images of ferrite microstructure for (a) 40010 sintered at $950^{\circ} \mathrm{C} / 2 \mathrm{hours}$ and (b) 40011 sintered at $885^{\circ} \mathrm{C} / 3$ hours, (c) (d) $U 70$ and U200 sintered at $980^{\circ} \mathrm{C} / 2$ hours 

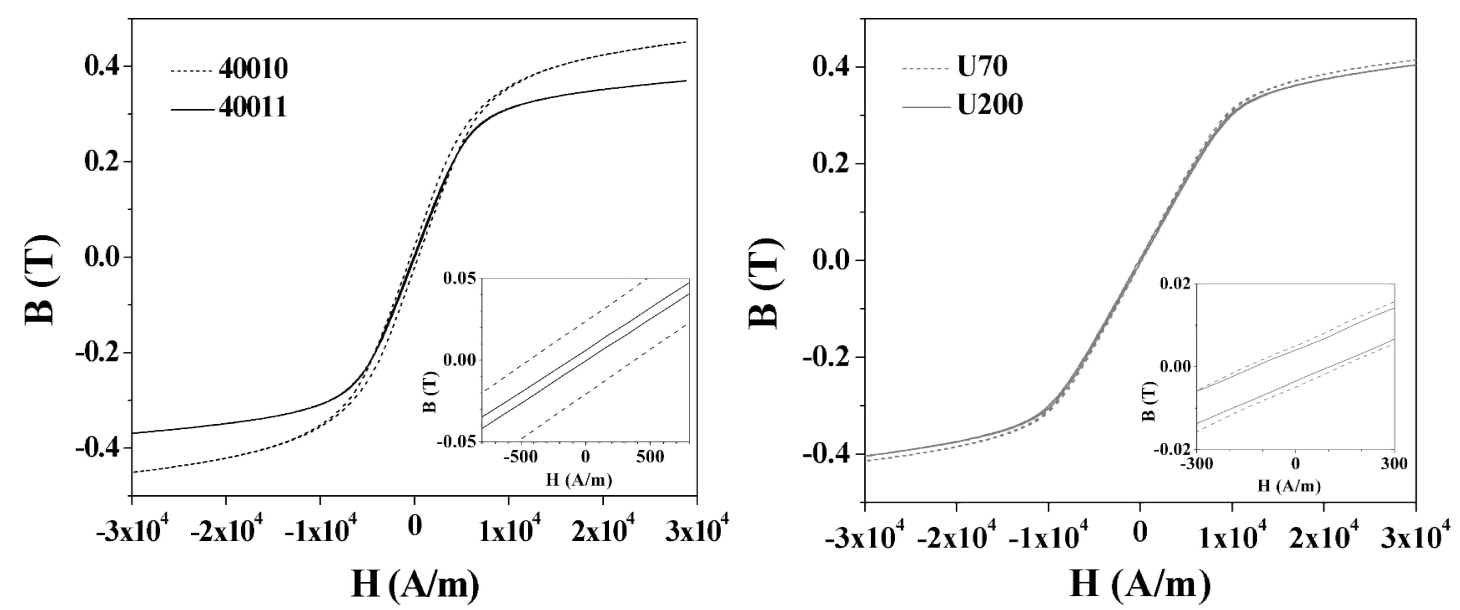

Figure 4. B-H curves of thin film ferrite measured by VSM

\subsection{Electrical characterization}

The complex permeability of each material (40010, 40011, U70 and U200) was extracted as a function of frequency (as shown in figure 5) from impedance measurements of ferrite tores mounted on the magnetic test fixture using the following equation:

$$
\mu_{r}^{*}=\frac{2 \pi\left(Z_{m}^{*}-Z_{s m}^{*}\right)}{j \omega \mu_{0} h \ln \frac{c}{b}}+1
$$

in which $Z_{m}^{*}$ is the impedance of the test fixture with the tore and $Z_{s m}^{*}$ is the impedance of the test fixture without the tore; $\omega$ is measurement pulsation $\omega=2 \pi f, \mu_{0}$ is permeability of free space, $h$ is thickness of the tore; $c$ and $b$ are external and internal diameter of the tore respectively.

40011 ferrite presents a permeability of 200 stable up-to $10 \mathrm{MHz}$ while that value for 40010 is 60 and stable until $70 \mathrm{MHz}$. These measured values correspond to values provided by ESL. The secondary permeability of 40010 at zero DC and small AC signal is small up-to $50 \mathrm{MHz}$, whereas that of 40011 increases quickly from 1-3 MHz. Higher secondary permeability ( $\mu$ ") means higher losses. U70 and U200 have permeabilities of 86 and 190 stable up to $50 \mathrm{MHz}$ and $10 \mathrm{MHz}$ respectively. When comparing U200 with 40011 films at $6 \mathrm{MHz}$, which is the frequency of interest: both show high primary permeability. However, secondary permeability for 40011 films is much higher than U200 film. We thus expect higher core loss density for 40011 than for U200 under the same operating conditions. Losses of U200 ferrite are small thanks to the cobalt contribution, as reported by Lucas [33]. Table 2 summarizes magnetic properties of selected ferrites.

Table 2: Magnetic properties of different ferrites

\begin{tabular}{|l|l|l|l|l|}
\hline & $\mathbf{4 0 0 1 1}$ & $\mathbf{4 0 0 1 0}$ & U200 & U70 \\
\hline Permeability $\boldsymbol{\mu}$ ' & 200 & 60 & 190 & 86 \\
\hline $\begin{array}{l}\text { Induction saturation } \\
\boldsymbol{B}_{\boldsymbol{s}}(\mathbf{T})\end{array}$ & 0.25 & 0.30 & 0.25 & 0.25 \\
\hline Coercive field $\boldsymbol{H}_{\boldsymbol{c}}(\mathbf{O e})$ & 0.8 & 5.8 & 1.5 & 1.9 \\
\hline $\begin{array}{l}\text { Resonance frequency } \\
\boldsymbol{F}_{\text {res }}(\mathbf{M H z})\end{array}$ & 30 & 100 & 30 & 100 \\
\hline
\end{tabular}


Electrical characterizations were performed for different magnetic cores with 21-turn coil. Figure 6 a) shows the inductance of test inductors as a function of frequency. An inductance as high as $860 \mathrm{nH}$ corresponding to 215 $\mathrm{nH} . \mathrm{mm}^{-2}$ was obtained for the 40011 core and $287 \mathrm{nH}$ corresponding to $72 \mathrm{nH} . \mathrm{mm}^{-2}$ obtained for 40010 cores at 6 $\mathrm{MHz}$ while the air core inductor has only an inductance of $18 \mathrm{nH}$.
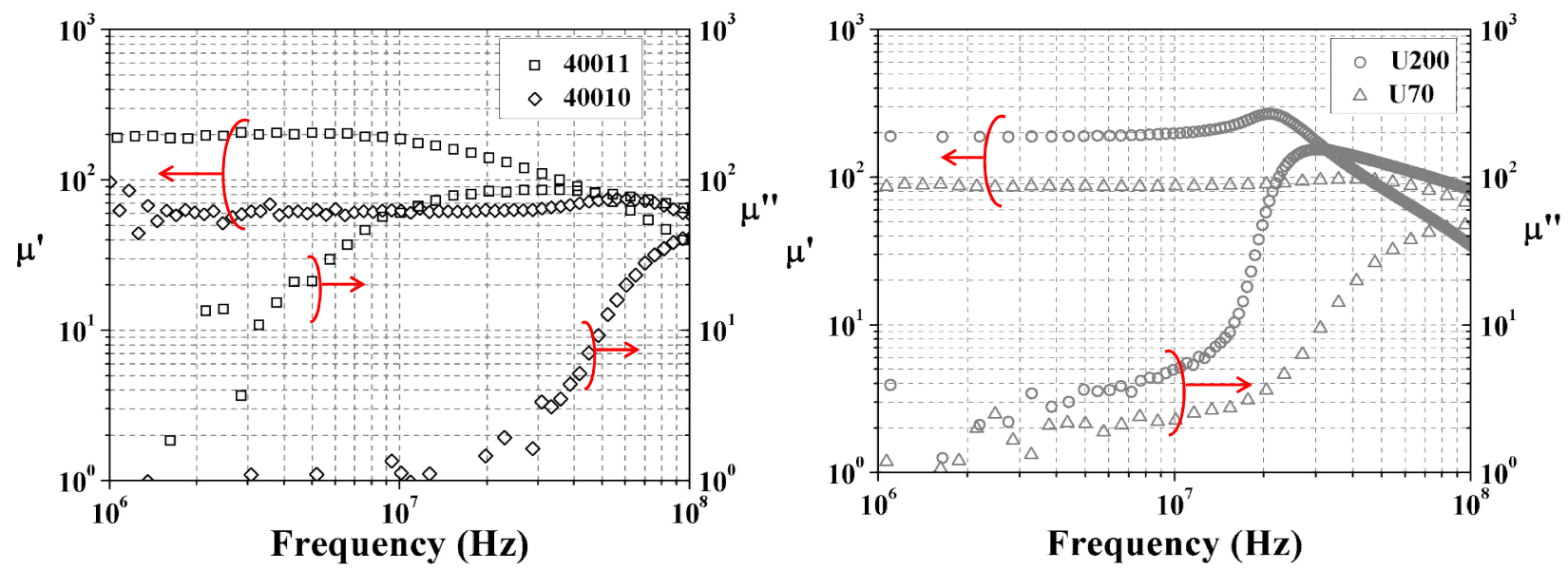

Figure 5. Measured complex permeability: ESL $40010 \AA$ and $40011 \AA$ ferrites sintered at $950^{\circ} \mathrm{C} / 2 \mathrm{~h}$ and $885^{\circ} \mathrm{C} / 3 \mathrm{~h}$ ( $b=4 \mathrm{~mm}, c=6 \mathrm{~mm}$ and $\mathrm{h}=108 \mu \mathrm{m}), U 70$ and $U 200$ home-made ferrites sintered at $980^{\circ} / 2 \mathrm{~h}(b=5 \mathrm{~mm}, c=14 \mathrm{~mm}$ and $h=1.5 \mathrm{~mm}$ )

These fully sintered ferrite cores offering high values of inductance density as demonstrated with the test inductors present thus a real advantage for realizing small rectangular micro-inductors on chips compared to other reported non-sintered ferrite inductors $[8,26,28]$. Figure 6 b) shows the inductance versus superimposing DC bias current for the four films. The inductance drops quite rapidly, especially for 40011 and U200 ferrites. This is due to the non-linearity of the permeability versus DC magnetic field. The decrease of $\mu$ versus pre-magnetization field was already observed by $\mathrm{Mu}$ et al [24]. The higher the permeability, the more severe is the drop. This behavior is a major drawback and it will have to be taken into account in the design optimization of micro-inductors. Meanwhile, 40010 cores have permeability more stable with DC bias current, yet they have lower permeability (see figure 5 a) and figure $6 \mathrm{~b})$ ).
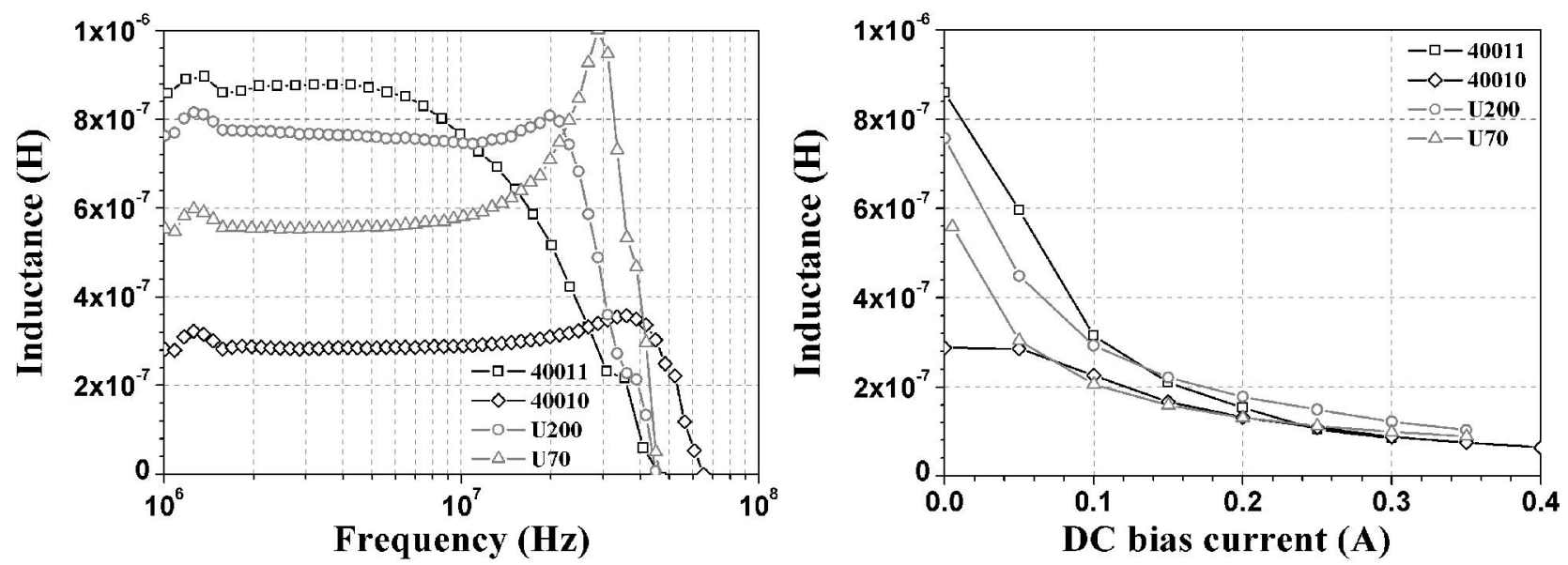

Figure 6. Measured inductance of the test inductors made of different cores as functions of a) frequency and $b$ ) 


\subsection{Core losses}

For design purposes, it is important to extract core losses at different excitation conditions: AC, DC and frequency. In soft ferrite films, core losses include eddy current losses, hysteresis losses and residual losses. The total core losses per unit volume were extracted from under-probe measurements of test inductors with varying sine-wave signal using equation (2):

$$
P_{v}=\frac{R_{S} I_{A C}^{2}}{A_{e} l_{e}}
$$

$R_{S}$ is obtained by subtracting the resistance of air-core inductor from the resistance of magnetic-core inductor. $I_{A \mathrm{C}}$ is the alternating current (rms), $A_{e}$ is the effective magnetic cross section and $l_{e}$ is the mean magnetic length.

Figure 7 shows extracted core losses versus frequency for the 40011 film. Measurement is carried out at different levels of sine wave signal $I_{A C}(\mathrm{rms})$. The induction variation is referred from AC current by Eq. (3) in which $L_{s}$ is the difference of impedance's imaginary parts from magnetic-core inductor and air-core inductor divided by the measurement pulsation $\omega$. As expected, losses increase with frequency and with sine wave amplitude.

$$
B_{A C}=\frac{L_{s} * I_{A C}}{N * A_{e}}
$$

Analytical models of core losses were generated by fitting the datasheet curve $P_{v}$ in the range of $1-10 \mathrm{MHz}$ using Steinmetz equation (4) with a least squares method [36,37]. Steinmetz equation works well for ferrite losses with sine-wave signal (see fitting in figure 7). Similar curves were produced for the three other materials. Table 3 summarizes the parameters $\mathrm{k}, \alpha$ and $\beta$ of four materials for the frequency range $1-10 \mathrm{MHz}$ and at zero DC bias.

$$
P_{v}=k * f^{\alpha} * B_{A C}^{\beta}
$$

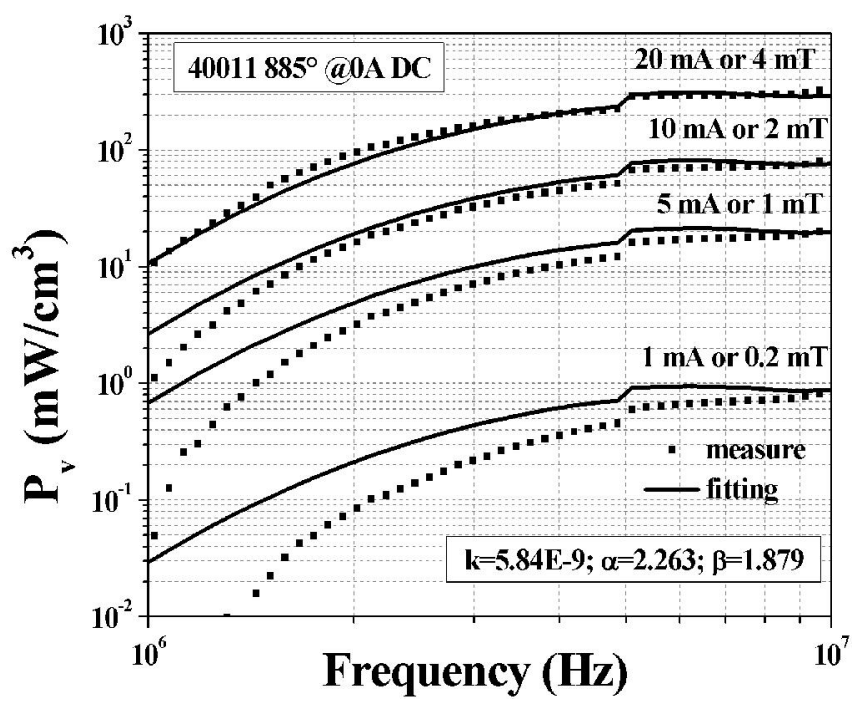

Figure 7. Measured and analytical core losses versus frequency for 40011 films 
Table 3: Values of parameters $k$, $\alpha$ and $\beta$ obtained for four materials at zero DC bias, apply for frequency 1-10 $\mathrm{MHz}$ and $B_{A C}=0.1-10 \mathrm{mT}$

\begin{tabular}{|l|r|r|r|}
\hline Ferrites & k & \multicolumn{1}{|c|}{$\boldsymbol{\alpha}$} & \multicolumn{1}{|c|}{$\boldsymbol{\beta}$} \\
\hline 40011 & $5.84 \mathrm{E}-09$ & 2.263 & 1.879 \\
\hline 40010 & $1.199 \mathrm{E}-09$ & 2.356 & 1.969 \\
\hline U200 & $4.084 \mathrm{E}-07$ & 1.878 & 1.601 \\
\hline U70 & $6.049 \mathrm{E}-10$ & 2.345 & 1.869 \\
\hline
\end{tabular}

For comparison purposes, core losses of the four studied materials versus magnetic induction, at two frequencies $(1.5$ and $6 \mathrm{MHz}$ ) are presented in figure 8. These curves were generated from analytical loss models: experimental data points are also shown. 40010 and U70 cores show the smallest losses. As shown in figure 7, 40011 core exhibits losses about $300 \mathrm{~mW} . \mathrm{cm}^{-3}$ at $4 \mathrm{mT}$ and $5 \mathrm{MHz}$, comparable with the reported value of $400 \mathrm{~mW} . \mathrm{cm}^{-3}$ for the same conditions by $\mathrm{Mu}$ et al. [24]. At $10 \mathrm{mT}$, U200 core presents lower losses than 40011: about $100 \mathrm{~mW} . \mathrm{cm}^{-3}$ at 1.5 $\mathrm{MHz}$ which is in the range of already reported results for this material by Lucas, i.e. $200 \mathrm{~mW} \cdot \mathrm{cm}^{-3}$ at $25 \mathrm{mT}$ [33]. At $6 \mathrm{MHz}$, all losses increase by a factor of 30: at induction value of $10 \mathrm{mT}$, losses reach levels of 1500-2500 mW.cm for U200 and 40011 ferrites.
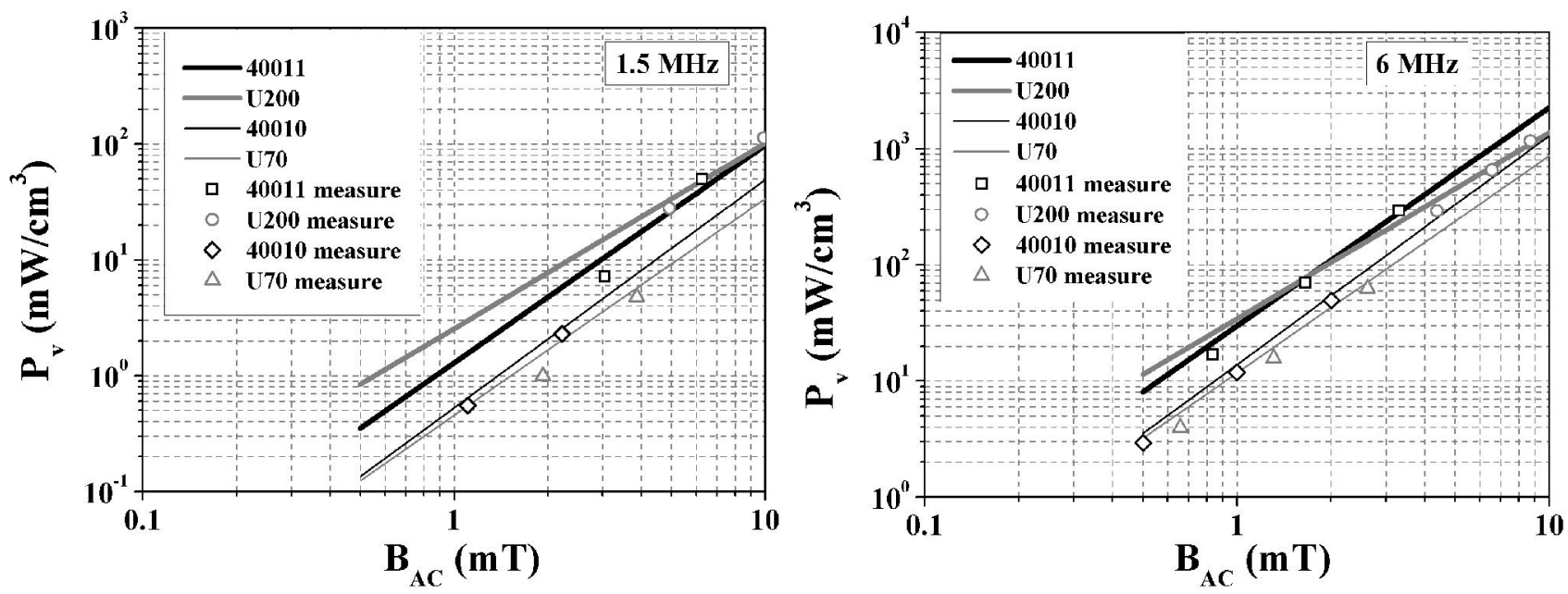

Figure 8. Core losses of four materials as a function of induction variation at $1.5 \mathrm{MHz}$ and $6 \mathrm{MHz}$

\subsection{Effect of sintering temperature}

The choice of sintering temperature for ferrites is based on the TMA curves. As shown figure 9, the solid state reactions happen from $850^{\circ} \mathrm{C}$ to $950^{\circ} \mathrm{C}$ for 40011 . The sintering temperature should fall in this range. In this work, we give the comparison for two sintering temperatures $885^{\circ}$ and $950^{\circ}$. The effect of sintering temperature on the properties of 40011 ferrite was studied. 


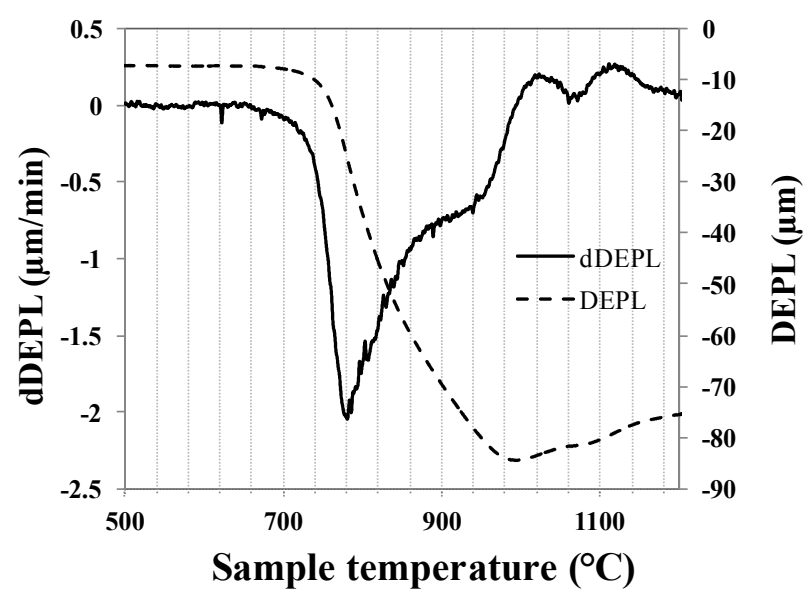

Figure 9. Thermomechanical analysis of 40011 ferrite; DEPL is the deplacement of the sample, dDEPL is the derivative of the deplacement.

It is shown that sintering at higher temperature makes the micro-structure of ferrites coarser. Bigger grains are formed at higher sintering temperature (see figure 10). Concerning magnetic properties, higher sintering temperature brings higher permeability. 40011 cores show a permeability of 300 for sintering temperature of $950^{\circ} \mathrm{C}$ and 200 for sintering temperature of $885^{\circ} \mathrm{C}$ (see figure 11). This phenomenon can be explained by Globus model [38]: at low induction condition, domain wall bulging, instead of domain wall displacement, is responsible for $\mu^{\prime}$. According to this model, $\mu^{\prime}$ increases with the increasing distance between pinned edges of domain wall, which is approximately equal to grain size. However, the disadvantages are: the cores sintered at higher temperature have higher losses and a lower cut-off frequency (see figure 12 and 11). Core losses include hysteresis loss, eddy current loss and residual loss in which eddy current loss is considered negligible because of the high resistivity of selected ferrites. Under low induction condition, the hysteresis loss is smaller for smaller grain size [39]. Hence, total core losses are smaller for 40011 sintered at $885^{\circ} \mathrm{C}$ compared to $950^{\circ} \mathrm{C}$. Magnetic properties and extracted loss coefficients of 40011 cores are presented in table 4 and table 5.
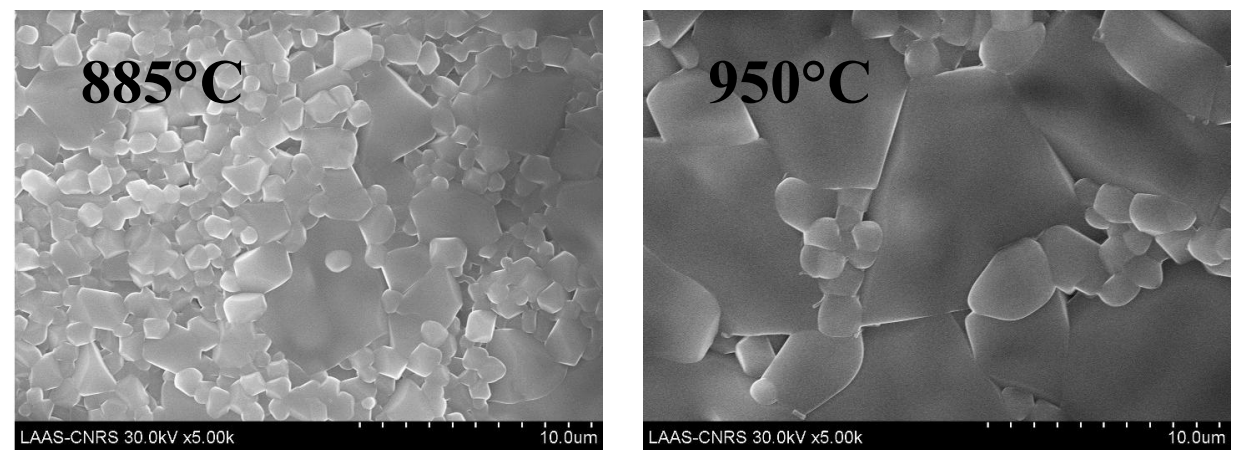

Figure 10. Effect of sintering temperature on microstructure of 40011 ferrite 


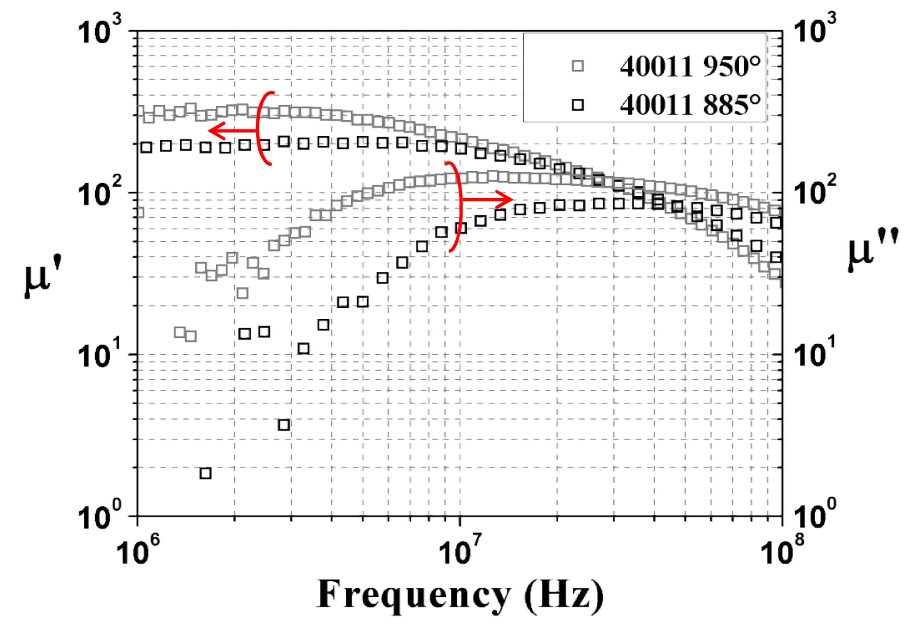

Figure 11. Complex permeability of 40011 cores sintered at different temperature

Table 4: Magnetic properties of 40011 sintered at different temperature

\begin{tabular}{|l|l|l|}
\hline $\mathbf{4 0 0 1 1}$ & $\mathbf{8 8 5}^{\circ} \mathbf{C}$ & $\mathbf{9 5 0}^{\circ} \mathbf{C}$ \\
\hline Permeability $\boldsymbol{\mu}^{\prime}$ & 200 & 300 \\
\hline Induction saturation $\boldsymbol{B}_{\boldsymbol{s}}(\mathbf{T})$ & 0.25 & 0.25 \\
\hline Coercive field $\boldsymbol{H}_{\boldsymbol{c}}(\mathrm{Oe})$ & 0.8 & 1.9 \\
\hline Resonance frequency $\boldsymbol{F}_{\text {res }}(\mathbf{M H z})$ & 30 & 10 \\
\hline
\end{tabular}

Table 5: Loss coefficients at zero DC bias for 40011 cores sintered at two temperatures fitted with Eq. 4, apply for frequency 1-10 MHz and $B_{A C}=0.1-10 \mathrm{mT}$. (Measurement results not shown here).

\begin{tabular}{|l|l|l|l|}
\hline Ferrites & \multicolumn{1}{|c|}{$\mathbf{k}$} & \multicolumn{1}{|c|}{$\alpha$} & \multicolumn{1}{|c|}{$\beta$} \\
\hline $40011885^{\circ} \mathrm{C}$ & $5.84 \mathrm{E}-09$ & 2.263 & 1.879 \\
\hline $40011950^{\circ} \mathrm{C}$ & $2.438 \mathrm{E}-08$ & 2.226 & 1.89 \\
\hline
\end{tabular}

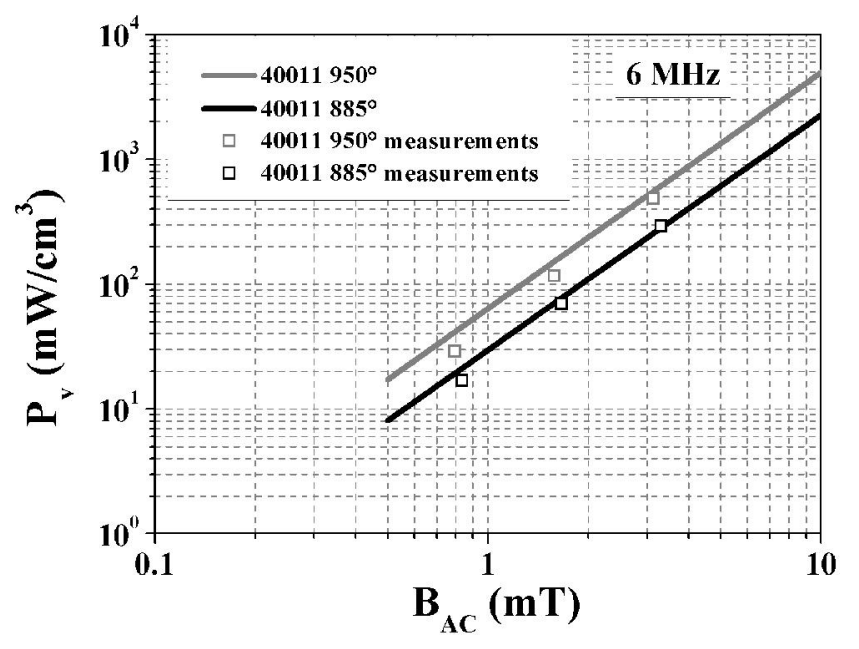

Figure 12. Losses of 40011 cores sintered at different temperature 


\section{Conclusions and perspectives}

Ferrite-based rectangular cores were fabricated via two techniques: screen printing and milling of commercial green tape films and their performance evaluated. Chosen ferrites are very interesting in terms of permeability. Test inductors containing these ferrite cores achieve a very high inductance density above already reported micro ferrite inductors thanks to the pre-eminent magnetic properties of fully sintered ferrite. In this work, it was shown that at 6 $\mathrm{MHz}, 215 \mathrm{nH} . \mathrm{mm}^{-2}$ of inductance could be reached for test inductors including 40011 cores and $72 \mathrm{nH} . \mathrm{mm}^{-2}$ for the ones including 40010 cores. However, when superimposing a DC bias current, all four materials chosen for core fabrication exhibit a large decrease of permeability, which is a potential disadvantage of these soft ferrite cores for high DC current application. In term of losses, 40010 and U70 have the smallest losses about $1 \mathrm{~W} . \mathrm{cm}^{-3}$ at $6 \mathrm{MHz}$ under $10 \mathrm{mT}$. U200 and 40011 losses range between 1.5 and $2.5 \mathrm{~W} \cdot \mathrm{cm}^{-3}$ respectively under the same conditions; U200 and 40011 ferrites could be chosen when high inductance density is desired for the micro-inductor. Further work is needed to measure losses and extract corresponding models for higher induction levels and for additional static magnetic fields. Optimization for design of future micro-inductors including these ferrite films is to be done with the consideration of the losses models developed. Final micro-inductors will be realized by thick photo-resist method to insulate ferrite cores and deposit copper tracks on top. X-ray characterization will be carried out to give information regarding the structure of materials. Dielectric constants will be measured at different frequencies to study the capacitive character of these ferrites.

\section{Acknowledgement}

This work was funded by PRIIM project using micro fabrication platform at LAAS (supported by French RENATECH network) and 3DPhi platform at LAPLACE. VSM measurements were done at ONERA and CIRIMAT (Toulouse, France): we thus kindly thank Isabelle Séguy, Matthieu Palosse, Le Trong Hoa and M. Gougeon for performing the measurements. We would like also to thank Frédéric Voiron from IPDIA and JeanPhilippe Michel from CEA-Léti for fruitful discussions on the subject during PRIIM project. Thanks to ESL ElectroScience for providing us samples of ESL 40011® and ESL 40010® films.

\section{References}

[1] Wang N, O'Sullivan E J, Herget P, Rajendran B, Krupp L E, Romankiw L T, Webb B C, Fontana R, Duch E A, Joseph E A, Brown S L, Hu X, Decad G M, Sturcken N, Shepard K L and Gallagher W J 2012 Integrated on-chip inductors with electroplated magnetic yokes (invited) Journal of Applied Physics $11107 \mathrm{E} 732$

[2] Lu S, Sun Y, Goldbeck M, Zimmanck D R, Sullivan C R 2007 30-MHz power inductor using nano-granular magnetic material. In: 38th IEEE Power Electronic Specialists Conference, Orlando, FL 1773-6

[3] Flynn D and Desmulliez M P Y 2009 Design, Fabrication, and Characterization of Flip-Chip Bonded Microinductors IEEE Transactions on Magnetics 45 3055-63

[4] Kowase I, Sato T, Yamasawa K and Miura Y 2005 A planar inductor using Mn-Zn ferrite/polyimide composite thick film for lowvoltage and large-current DC-DC converter IEEE Transactions on Magnetics 41 3991-3

[5] Lee D W, Hwang K-P and Wang S X 2008 Fabrication and Analysis of High-Performance Integrated Solenoid Inductor With Magnetic Core IEEE Transactions on Magnetics 44 4089-95

[6] Wang N, O'Donnell T, Roy S, McCloskey P and O'Mathuna C 2007 Micro-inductors integrated on silicon for power supply on chip Journal of Magnetism and Magnetic Materials 316 E233-E7

[7] Mathuna C O, Wang N, Kulkarni S and Roy S 2012 Review of Integrated Magnetics for Power Supply on Chip (PwrSoC) IEEE Transactions on Power Electronics 27 4799- 816

[8] Fukuda Y, Inoue T, Mizoguchi T, Yatabe S and Tachi Y 2003 Planar inductor with ferrite layers for DC-DC converter IEEE Transactions on Magnetics 39 2057-61 
[9] Meyer C D, Bedair S S, Morgan B C and Arnold D P 2012 Influence of Layer Thickness on the Performance of Stacked ThickFilm Copper Air-Core Power Inductors IEEE Transactions on Magnetics 484436 - 9

[10] Jia H, Lu J, Wang X, Padmanabhan K and Shen Z J 2011 Integration of a Monolithic Buck Converter Power IC and Bondwire Inductors With Ferrite Epoxy Glob Cores IEEE Transactions on Power Electronics 26 1627-30

[11] Liakopoulos T, Panda A, Wilkowski M, Lotfi A, Tan K H, Zhang L, Lai C and Chen D 2012 Introducing FCA, a New Alloy for Power Systems on a Chip and Wafer Level Magnetic Applications 13th International Conference on Electronic Packaging Technology \& High Density Packaging (Icept-Hdp 2012) 948-53

[12] Kim J, Kim M, Herrault F, Park J and Allen M G 2013 Highly Laminated Soft Magnetic Electroplated CoNiFe Thick Films IEEE Magnetics Letters 45000204

[13] Lee J, Hong Y K, Bae S, Jalli J, Park J, Abo G S, Donohoe G W and Choi B C 2011 Integrated Ferrite Film Inductor for Power System-on-Chip (PowerSoC) Smart Phone Applications IEEE Transactions on Magnetics 47 304-307

[14] Harburg D V, Khan G R, Herrault F, Kim J, Levey C G and Sullivan C R 2013 On-chip RF power inductors with nanogranular magnetic cores using prism-assisted UV-LED lithography Solid-State Sensors, Actuators and Microsystems, 2013 Transducers \&

Eurosensors XXVII: The 17th International Conference (IEEE, Barcelona, 2013) 701-4

[15] Yu X, Kim J, Herrault F and Allen M G 2014 Silicon-embedded toroidal inductors with magnetic cores: Design methodology and experimental validation Applied Power Electronics Conference and Exposition (APEC), 29th Annual (IEEE, Fort Worth, TX) 763-7

[16] Lee F C, and Li Q 2013 High-Frequency Integrated Point-of-Load Converters: Overview IEEE Transactions on Power Electronics 28 4127-36

[17] Harburg D V, Hanson A J, Yue S, Qui J, Tian R, Christopher G L,Charles R S and David O 2013 Measured performance and micro-fabrication of racetrack power inductors Energy Conversion Congress and Exposition (ECCE) 2013 (IEEE, Denver, CO) 614-20

[18] Meere R, Wang N, O'Donnell T, Kulkarni S, Roy S, and O'Mathuna S C 2011 Magnetic-Core and Air-Core Inductors on Silicon: A Performance Comparison up to $100 \mathrm{MHz}$ IEEE Transactions on Magnetics 47 4429-32

[19] Kim J, Kim J K, Kim M, Herrault F and Allen M G 2013 Microfabrication of toroidal inductors integrated with nanolaminated ferromagnetic metallic cores Journal of Micromechanics and Microengineering 23114006

[20] Sugawa Y, Ishidate K, Sonehara M and Sato T 2013 Carbonyl-Iron/Epoxy Composite Magnetic Core for Planar Power Inductor Used in Package-Level Power Grid IEEE Transactions on Magnetics 49 4172-5

[21] Bharadwaj S, Ramesh T and Murthy S R 2013 Fabrication of microinductor using Nanocrystalline NiCuZn ferrites Journal of Electroceramics 31 81-7

[22] Mu M, Zhang W, Lee F C and Su Y 2013Laminated low temperature co-fired ceramic ferrite materials and the applications for high current POL converters Energy Conversion Congress and Exposition (ECCE) (IEEE, Denver, CO) 621-7

[23] Zhang W, Su Y, Mu M, Gilham D J, Li Q and Lee F C 2014 High Density Integration of High Frequency High Current Point-ofLoad (POL) Modules with Planar Inductors IEEE Transactions on Power Electronics pp 1

[24] Mu M, Su Y, Li Q, Lee F C 2011 Magnetic Characterization of Low Temperature Co-fired Ceramic (LTCC) Ferrite Materials for High Frequency Power Converters 2011 IEEE Energy Conversion Congress and Exposition (ECCE) 2133-8

[25] Bae S, Hong Y K, Lee J J, Jalli J, Abo G S, Lyle A, Choi B C and Donohoe G W 2009 High Q Ni-Zn-Cu Ferrite Inductor for OnChip Power Module IEEE Transactions on Magnetics 45 4773-6

[26] Bang D H and Park J Y 2009 Ni-Zn Ferrite Screen Printed Power Inductors for Compact DC-DC Power Converter Applications

IEEE Transactions on Magnetics 45 2762-5

[27] Fang X, Wu R, Peng L and Sin J K O 2013 A Novel Silicon-Embedded Toroidal Power Inductor With Magnetic Core IEEE

Electron Device Letters 34 292-4

[28] Wang M L, Li J P, Ngo K D T and Xie H K 2011 A Surface-Mountable Microfabricated Power Inductor in Silicon for

Ultracompact Power Supplies IEEE Transactions on Power Electronics 26 1310-5

[29] Nguyen Y M, Brunet M, Laur J P, Bourrier D, Charlot S, Valdez-Nava Z, Bley V and Combettes C 2013 Low-profile small-size ferrite cores for powerSiP integrated inductors Power Electronics and Applications (EPE), 15th European Conference (IEEE, Lille) pp 1-7

[30] Nguyen Y M, Brunet M, Laur J P, Bourrier D, Charlot S, Valdez-Nava Z, Bley V and Combettes C 2013 Soft ferrite cores characterization for integrated micro-inductors 13th International Conference on Micro- and Nano-Technology for Power Generation and Energy Conversion Applications (PowerMEMS)Imperial Coll London, London, England, J. Phys.: Conf. Ser. 476012139

[31] ESL 40010® datasheet

[32] ESL 40011® datasheet

[33] Lucas A 2012 Etude et mise au point de transformateurs large bande radiofréquence. In: L'Ecole normale superieure de Cachan,

(ENS Cachan/CNRS/UMR 8029: L'Ecole normale superieure de Cachan)

[34] LPS3010 inductor by Coilcraft http://www.coilcraft.com/lps3010.cfm

[35] Caltun F O, Spinu L and Stancu A 2001 Magnetic properties of high frequency Ni-Zn ferrites doped with CuO IEEE Transactions on Magnetics 37 2353-5

[36] Sullivan C R 2012 Overview of core loss prediction for non-sinusoidal waveforms. In: APEC: Dartmouth Magnetic Components and Power Electronics Research Group

[37] Havez L 2013 3D Power Inductor: Calculation of Iron Core Losses. ed Y L E. Sarraute Proceedings of the 2013 COMSOL conference in Rotterdam

[38] Globus A 1977 Some physical considerations about domain-wall size theory of magnetization mechanisms Journal De Physique 38

$1-15$

[39] Kondo K, Chiba T, and Yamada S 2003 Effect of microstructure on magnetic properties of Ni-Zn ferrites Journal of Magnetism and Magnetic Materials 254 541-3 